\title{
Is there a doctor in the house?
}

\section{H Rubin}

As out-of-hospital emergencies become more commonplace, so does the call for a "doctor in the house". New York City paediatrician Mitchell Rubin has responded to numerous such crises over the past 25 years. He explores reactions on all sides of this peculiar physician-victim relationship, his growing concerns and fears, and possible reasons why many doctors hesitate to act. His thoughts and experiences instigate the discussion about the need for a universal system of Good Samaritan physician responders

W hile flying to Italy last spring, the pilot's voice came over the loudspeaker: "Is there a doctor on board"? How many times have I heard this request in the last 25 years? A passenger had fainted. As I began caring for her, the pilot asked me, "Should we take the plane down?". Surprised to be given this responsibility, I took my best guess and answered "no". After a stressful landing, while I gave oxygen to the prostrate woman, we were met by an ambulance on the tarmac. The woman was appreciative and gracious, the pilot scarcely offered thanks, and I began my vacation exhausted.

Having been trained as a paediatrician, I have responded to nearly two dozen "Good Samaritan" scenarios, where a person was injured or became critically sick in a public setting. Perhaps I have had more than my fair share, but I wonder if this is an important and mounting phenomenon. With America growing older and more and more people with serious, chronic illnesses remaining active in the community, we should not be surprised to see increasing numbers of out-of-hospital emergencies. And, as this becomes more commonplace, I become less and less certain of the role I-and other physicians like me-should have.

When I was young, cocky and fearless, the call to meet an emergency was exciting. Shortly after training, an adult experienced chest pain during a religious service. As I responded, my reservations were few and my level of confidence was high. I was a doctor, and I was thrilled to be able to help.

But that was 25 years ago! As a resident, the urgent cry to attend a $\mathrm{C}$ section for fetal distress beckoned me into a focused zone. Bring it on, I thought, as my mind whirled through possible complications, lists of drugs and high-tech instruments at my disposal. In my nai- veté, I believed a more capable doctor could not have been found to deal with such a potential catastrophe. But in subsequent years, my routine work has become distant from such dire emergencies, rarely requiring the need to make instantaneous life and death decisions.

Now, when I hear "the call" on the street, my pulse quickens and I transform like Clark Kent, reassuringly removing my glasses, introducing myself as a "physician", and taking on the crisis. The assurance I felt as a resident has been clouded by time and new concerns. Although there is no turning back for me, I pray for a false alarm-that all is well in Gotham. And if not, I hope I will be faced with a familiar malady, or at least that someone else, with more relevant expertise, will take charge. How relieved I am when emergency medical service arrives or if other "doctors in the house" come forward.

\section{AM I QUALIFIED?}

Am I actually qualified to deal with the emergency? Although certified in cardiopulmonary resuscitation, and having practised for over two decades, my concentration has shifted from emergency room acrobatics and intensive care procedures to rashes, ear aches and common community maladies. As for trauma and heart attacks and the like, perhaps I am not the best person for the job. But, as the request is sounded, I continue to move into action.

I have had many discussions with my lifeguard stepson, who argues that he is more capable than many physicians in treating out-of-hospital trauma. I argue valiantly for "our team", invoking the physician's vast experience and wisdom. But he may have a point. Society considers physicians the best-trained and highest form of healers. No one ever yells, "Is there a paramedic in the house?". But
I am unsure if we, as a group, are given too much credit and credibility for handling these situations.

When the call goes out for a "doctor", it is clearly not intended to attract PhDs. But including all medical doctors may still be too broad. When was the last time a radiologist had touched a patient? Dare I announce to the family of the octogenarian, clutching his chest, that I am a paediatrician? Frankly, if I needed stabilisation after a car wreck, a lifeguard, rather than a dermatologist long out of training, might be my choice. Furthermore, if there is more than one responder, who is in charge? What is a logical authoritative hierarchy? Do surgeons trump psychiatrists? Should an emergency room nurse outrank an ophthalmologist? Where does a general paediatrician stand?

\section{WHAT ARE THE RISKS?}

Unfortunately, in my experience, the question of who is most qualified does not often come into play because when the pilot, the rabbi or the restaurateur cries out, I am the only one to rise. In some of these settings, I am certain I am not the only MD there. What is holding the others back? A review of the literature on physicians as Good Samaritans is scarce. "The Physician as Ambivalent Samaritan"1 determined that the most common reason for the not uncommon unwillingness to help victims of out-ofhospital emergencies was a reluctance to provide mouth-to-mouth resuscitation. Catching germs is not my issue, but other matters do come to mind, and I suspect I am not alone in thinking of them.

As the alarm sounds, I now consider my risks. Whether assisting an elderly person who has fallen, or providing cardiopulmonary resuscitation to a person having a stroke, I cannot help but wonder if I might be sued. I am middle aged, having acquired a mortgage, kids in college and a lifestyle that does not encourage risk. Although my gut response is unambiguous, and so I act, legal considerations surface. From medical school onwards, we doctors have heard about the Good Samaritan Law and how it shields our hallowed fraternity. Yet the truth is that it is not exactly airtight. Although this doctrine generally affords protection, there are grey areas. People (including physicians) are rarely sued for helping in an emergency, but the existence of Good Samaritan laws, which differ from state to state, does not guarantee that someone cannot be sued, nor does it provide immunity from malpractice claims. Ill-defined terms, such as "good faith" and "reasonable", are typically in this legislation, leaving even 
well-intentioned actions subject to interpretation. Do not even ask about a Good Samaritan's rights if injured while responding, or about international occurrences.

\section{WHAT ARE THE EXPECTATIONS?}

One Saturday night in Manhattan, as my wife and I were dining, the owner sounded the all-too-familiar cry. I jumped out of my seat to find a pale, elderly man lying on the floor. As he lost his pulse, I removed his dentures (how did I remember that?), began mouth-to-mouth resuscitation and chest compressions, his fragile ribs cracking under my thrusts. Yet, the world of the restaurant continued around me-waiters bustled, the bar was lively and a line continued to grow at the nearby reception area. Finally, after an excruciatingly long time, emergency medical service arrived, and applied countless rounds of electroshock. The gentleman was dead; I was numb. While the paramedic empathetically patted me on the shoulder, the restaurateur offered nothing more than a drink "on the house". He treated my frightening and draining effort as something on par with a 10min seating delay.
Such a curious attitude and response has been shown in a variety of settings. Normally, when one holds a door open, a "thank you", or a warm nod closes the social circuit. In Good Samaritan situations, doctors and other providers are assuming risk of reputation and livelihood. My experience suggests that the individual victim and family often express their thanks. And other emergency workers seem grateful to have someone else step in. But I am repeatedly baffled by the lack of acknowledgement by those "in charge" of the public places where these emergencies have occurred. Pilots, restaurateurs and even clergy have acted as if I were on "staff", expected and required to meet the urgent needs of their passenger, diner or congregant, without any real recognition or appreciation. What is my responsibility? Are their expectations appropriate? Are mine?

The physician and victim, strangers no more, enter into a relationship based on assumptions and expectations. From my side, why would not I offer to help? Was not this the reason that I wanted to be a doctor in the first place? As I noted, the sufferer is typically appreciative. But what should I make of the "taken for granted" attitude shown by those who called for the doctor in the house? Is this a reflection of our nation's love-hate relationship with physicians? Perhaps society holds a different set of expectations and standards for this privileged group, assuming that the Hippocratic oath and the privilege itself include $24 / 7$ availability, duty and obligation as part of the deal.

As I said, maybe I have had more than my fair share. Maybe other physicians have rarely heard "the call". But I am guessing this question will be asked with increasing frequency. Are we comfortable relying on random physician expertise, availability and willingness to meet our emergency needs in the air or on the ground? It is time to figure this out.

J Med Ethics 2007;33:158-159.

doi: 10.1136/jme.2006.017111

Correspondence to: M H Rubin, Director Pediatric Residency Program, Woodhull Medical and Mental Health Center, Brooklyn, NY 11206 , USA; mhr28@cornell.edu

\section{REFERENCE}

1 Gross CP, Resiman AB, Schwartz MD. The physician as ambivalent Samaritan: will internists resuscitate victims of out-of-hospital emergencies? J Gen Intern Med 1998;13:491-4.

Important Research Assessment Exercise information for Journal of Medical Ethics authors in UK universities

We are aware of the important of the RAE deadline for actual publication of papers before $31^{\text {st }}$ December 2007. If you have a paper accepted but not yet published by JME and if it is one that you intend to submit to the RAE as one of your four submissions then please contact the Editor in Chief, Professor Søren Holm (hlomscardiff.ac.uk) as soon as possible.

We will do our best to publish all papers that have been accepted before June 2007 before the RAE deadline, if we have been notified that they will be submitted to the RAE.

Please note that RAE submissions will be made public by the RAE, so only tell us that you will submit a JME article to the RAE if you really mean it! 